\title{
Six sigma project selections using fuzzy network-analysis and fuzzy MADM
}

\author{
Hassan Farsijani $^{a}$, Mohsen Shafiei Nikabadi ${ }^{b *}$ and Hamidreza Amirimoghadam ${ }^{c}$
}

${ }^{a}$ Associate Professor, Department of Industrial Management, Shahid Beheshti University, Tehran, Iran

${ }^{b}$ Assistant Professor, Department of Industrial Management, Semnan University, Semnan, Iran

${ }^{c}$ Ph.D. student, Department of Industrial Management, Shahid Beheshti University, Tehran, Iran

\begin{tabular}{l}
\hline C H R O N I C L E \\
\hline Article history: \\
Received March 14, 2014 \\
Accepted August 20, 2014 \\
Available online \\
August 28 2014 \\
\hline Keywords: \\
Six Sigma \\
Fuzzy Analytical Network Process \\
Fuzzy Multiple Attribute Decision \\
Making \\
Fuzzy Logic \\
Project Selection \\
Decision Making \\
SAW \\
TOPSIS \\
Fuzzy VIKOR
\end{tabular}

Six Sigma is a philosophy of unremitting improvement and excellence in all aspects. The concept is a satisfactory modification process tool through customers, continuous improvement and stakeholder participation. Six Sigma is considered as statistical analysis, assessment scales and customer-oriented production accomplishments and it leads to defect production reduction. This paper recommends an approach to select Six Sigma projects using fuzzy multiple attribute decision making techniques composed with another concoction tool. Through insightful quarrying of literature, rudimentary criteria for selecting Six Sigma projects were revealed. The fundamental criteria were identified consuming the fuzzy hypothesis test. Having identified the most indispensable criteria, the weight of criteria were determined. Appling FANP techniques. Having calculated the weights pertinent to criteria through three methods, SAW, TOPSIS, and Fuzzy VIKOR, Six Sigma projects were introduced and prioritized. Applying the three methods engendered various results, which required the application of an amalgamation technique, entitled as Borda and it helped to clarify the final project rate.

(C) 2015 Growing Science Ltd. All rights reserved.

\section{Introduction}

Six Sigma simply means a measure of quality, which strives for near perfection (Neuman \& Cavanagh, 2000; Pyzdek, 2003). Six Sigma is a disciplined, data-driven method for eliminating defects in any process from manufacturing to transactional and from any kind of product to different services. The statistical representation of Six Sigma explains quantitatively how a process is accomplished. To achieve Six Sigma, a process does not have to produce more than 3.4 defects per million opportunities. The primary objective of the Six Sigma methodology is to implement a measurement-based strategy, which concentrates on process improvement and variation reduction through the application of Six Sigma improvement projects (Adams et al., 2003). Several researchers have concentrated on the statistical characteristics of quality while some others preferred management point of view toward process improvement (Coronado \& Antony, 2002). Discovering the key factors in selecting Six Sigma projects leads to successful implementation of these projects and generate industrial growth and dynamism.

* Corresponding author.

E-mail address: mohsenshnaj@yahoo.com (M. Shafiei Nikabadi) 


\section{Literature review}

One of the primary key factors in Six Sigma execution is associated with project prioritization and selection (Breyfogle III et al., 2001; Eckes, 2000). Regarding the existence of various growth and improvement realm, organizations should select the projects that contest their strategy and ultimate goal (Ingle \& Roe, 2001). Büyüközkan and Öztürkcan (2010) proposed an integrated approach for Six Sigma project selection in which the criteria for it were introduced and assessed by DEMATEL and they applied analytical network process (ANP) to weigh the criteria leading to project selection. Burn (2010) introduced the major criteria in Six Sigma project selection in Italy and recommended that management and cultural alteration would be the principle factors for project selection. Six Sigma is a set of strategies, methods, and tools for process improvement and it was originally developed by Motorola in 1981. Six Sigma looks for improvement of the quality of process outputs by determining and removing the causes of defects (errors) and minimizing variability in manufacturing and business processes (Johnson \& Swisher, 2003).

The term Six Sigma initiated from terminology associated with manufacturing (specifically terms associated with statistical modeling of manufacturing processes). The maturity of a manufacturing process can be specified by a sigma rating indicating its yield or the percentage of defect-free products it generates. A six sigma process is one in which $99.9999998 \%$ of the items manufactured are expected to be free of defects, statistically (Linderman et al., 2003). The primary objective of Six Sigma is to improve all processes. Organizations need to determine an appropriate sigma level for each of their most important processes and do their best to achieve these objectives. Because of this goal, it is mandatory on management of the organization to prioritize areas of improvement (Coronado \& Antony, 2002). The term "six sigma processes" comes from the idea that if one has six standard deviations between the process mean and the nearest specification limit; practically no items will fail to meet specifications. This is grounded on the calculation method employed in process capability studies (Montgomery, 2001). Capability studies make an assessment on the number of standard deviations between the process mean and the nearest specification limit in sigma units, represented by $\sigma$ (sigma). As process standard deviation increases, or the mean of the process moves away from the center of the tolerance, fewer standard deviations may fit between the mean and the nearest specification limit, decreasing the sigma number and increasing the probability of items outside specification (Snee, 2004).

Six Sigma is a business strategy, which seeks to eliminate causes of errors or defects, defined as anything, which could lead to customer dissatisfaction or failures in business processes. It applied the normal distribution and a strong relationship between product Non-Conformities, or defects, and product yield, reliability cycle time, inventory, schedule, etc. (Snee, 2004). The activities of Six Sigma are not limited to process or operation levels, but they are extended to all the levels of an enterprise to reduce cost and produce high quality products. Six Sigma has been widely used in various industries as a proven management innovation methodology to produce high-quality products and reduce the cost at all the levels of an enterprise (Han \& Lee, 2002).

Six Sigma movements is also gaining acceptance in healthcare, marketing, engineering, financial and legal service organizations, in additions to achieve major benefits in the manufacturing sector (Snee, 2004). One of the Six Sigma key innovations is associated with professionalizing of quality management functions. For this reason, Six Sigma methodology determines several key roles for its successful implementation: executive leadership; champions (Eckes, 2000). In the same way, in the business world, Six Sigma is descibed as a business strategy used to improve business profitability, to improve the effectiveness and efficiency of all operations to meet or exceed customer's needs and expectations. It applies the normal distribution and a strong relationship between product NonConformities (NCs), or defects, and product yield, reliability, cycle time, inventory, schedule, etc. (Eckes, 2000; Brun, 2011). 
At the operational level, Six Sigma constructs on a set of well-established traditional methods and tools, as well as new techniques for setting important priorities on improvement and for measuring the monetary advantages. These new tools have to ensure that the additional objective of profitability improvement can be reached. Therefore, Six Sigma should not replace the already existing quality management methods, but it could improve them by getting into the organization. The result is a quality approach, which includes both traditional characteristics of total quality management (TQM) both Six Sigma quality philosophy (Wessel, 2003; Tadikamalla, 1994).

Six Sigma is about resolving business problems by improving processes where many typical problems fall into two major categories of identified solution, and unidentified solution and Six Sigma is aimed at solving the latter one. It could be claimed that a project is a problem scheduled for solution; and a Six Sigma project is described as a problem scheduled for solution, which applies a set of metrics to set project objectives and monitor progress. An organization's improvement plan normally embraces projects of both identified solution, and unidentified solution and both are needed to improve the performance of an organization. Solution-unknown projects are led by Black Belts or Green Belts. Solution-known projects are led by project managers (Ruffa, 2008).

The company should carefully identify and document the process, which encompasses the problem. The process provides the focus and context for the Six Sigma improvement work. Process identification is usually easy in manufacturing, but it is less recognizable in finance or marketing. To use Six Sigma, many firms take advantage of measurements, which quantify the magnitude of the problem and can be used to set project objects and monitor progress. These measurements are usually entitled as critical to quality (CTQ) measures. Six Sigma takes a methodical, rigorous approach to problem identification, diagnosis, analysis, and solution.

To select a six sigma project, some fact should be considered. Six Sigma project should be clearly connected to business priorities, strategic and annual operating plans. The problem should be of major significance for the firm, which means that the problem should yield significant improvement in process performance and key financial improvement. The scope of these projects have to be both specific and reasonable because support for project often decreases after 6 months so unnecessarily large scope is regarded as a critical problem. For the project success, a set of measurable quantitative criteria including are vital well-defined baseline, goals, and entitlement are essential. The project importance must be obvious to the organization because the stakeholders will support a project that they appreciate and perceive as important. In addition, the project requires the support and approval of top management, which leads to easy access to resources, barriers omission, and sustainability over time (Nonthaleerak \& Hendry, 2008).

Projects should be clearly allied to business priorities, as mirrored by the strategic and annual operating plans. It is also necessary to embrace projects addressing critical problems, which must be solved for future successes. A project should embody a breakthrough in terms of main improvements in both process performance and significant bottom-line results (Linderman et al., 2003). The determination of project effect is the concern of the financial organization working in cooperation with the Black Belt and Champion (Eckes, 2002). It is necessary that projects be completed in the specific time frame in order to retain the organization and resources concentrated on the project. Organizations typically miss interest in projects that run longer than their time scope. Projects requiring more time of effort can usually be divided into subprojects of shorter duration, with the projects being conducted sequentially or in parallel. For this approach to work a strong project management is essential to coordinate the set of projects (Azar \& Faraji, 2008). There should also be clear quantitative measures of success, the significance of the project to the organization should be clear, and the project should have the thorough support and endorsement of management. These three characteristics are required so that the organization sees the importance of the project, provides the needed support and resources, and removes barriers to the success of the project (Breyfogle III et al., 
2000). Project ideas can come from any source such as process assessments, customer and employee surveys and suggestions, benchmarking studies, extensions of existing projects, and so forth. Many try to learn on how to catch high-impact projects. Some recommended sources are: Rework and scrapping activities, Overtime, warranty, and other obvious sources of waste, Products with major backlogs - need for more capacity, High volume products (small improvements can have huge impact), Problems needing solutions to meet annual operating plan, Major problems with financial impact (customer or environmental crises), and Large budget items, receivables, payables, treasury, taxes (follow the money). Collectively, these ideas are concentrated on major sources of waste, major problems (customer and environmental), major opportunities (capacity limitations in sold-out markets), and places where the money is going (Montgomery, 2001).

For a project to be successful, the objectives need to be very clear. Such clarity is usually reflected in the process performance metrics and objectives associated with the project. The process metrics also has to be clearly defined baseline and entitlement values are identified. In the case of nonmanufacturing projects, the most useful process performance metrics are typically accuracy, cycle time, and cost. Cost is usually directly associated with accuracy and cycle time metrics. "Solving" can be interpreted in different ways. It could match to select the "best" alternative from a set of available alternatives. Another interpretation of "solving" could be choosing a small set of decent alternatives, or grouping alternatives into diverse preference sets. An extreme interpretation could be to catch all "efficient" alternatives. The toil of the problem initiates from the presence of more than one criterion. There is no longer a single optimal solution to multiple criteria decision making (MCDM) approach, which could be attained without incorporating preference information.

The notion of an optimal solution is often substituted by the set of non-dominated solutions. MCDM has been an active area of research since the 1970s (Köksalan et al., 2011). Fuzzy logic-first introduced by Zadeh (1968) and it has been applied to many fields, from control theory to artificial intelligence. Fuzzy logic deals with reasoning that is estimated rather than fixed and precise. Compared with traditional binary sets, fuzzy logic variables may have a truth value, which changes in degree between 0 and 1. Fuzzy logic has been prolonged to handle the concept of partial truth, where the truth value may range between completely true and completely false in fact classical logic only permits propositions having a value of truth or falsity (Nonthaleerak \& Hendry, 2008). Fuzzy logic and probability are dissimilar ways of conveying uncertainty. While both fuzzy logic and probability theory can be applied to symbolize subjective belief, fuzzy set theory slaves the concept of fuzzy set membership and probability theory exploits the concept of subjective probability. A fuzzy number is an extension of a regular number in the sense that it does not discuss one single value but rather a connected set of feasible values, where each imaginable value has its own weight between 0 and 1 . This weight is called the membership function. A fuzzy number is thus a special case of a convex, normalized fuzzy set of the real line. Calculations with fuzzy numbers help the incorporation of uncertainty on parameters, properties, geometry, initial conditions and so forth (Montgomery, 2001). In many studies, ANP, as a wide-ranging approach, was applied to solve many problems of decision making. In this research, Fuzzy Analytic Network Process (FANP) the new and powerful tool of fuzzy analytic network process is applied, which links fuzzy concepts with network analysis process. This method can be useful when the decision faced with several options and decision indicators. The theory of fuzzy system through using fuzzy logic theory and fuzzy sizes can enter parameters such as knowledge, experience and human judgment (Azar \& Faraji, 2008).

\section{Problem description}

This paper proposes an approach to select Six Sigma projects. A ship manufacturing company entitled as Sadra, encountered to a selection process among some six sigma projects, which were essential for its survival. The list of the projects to be elected among is as follow: 
$\mathrm{A}_{1}$ : manufacturing process improvement

$\mathrm{A}_{2}$ : Management and administration process improvement

$\mathrm{A}_{3}$ : Inventory management and storage process improvement

$\mathrm{A}_{4}$ : Marketing process improvement

$\mathrm{A}_{5}$ : Product design and development process improvement

Selection of an inappropriate six sigma project will lead to enormous strategic collapse and financial loss. Distinguishing the criteria for conducting selection process is another requirement of high importance. Lots of various styles are introduced for decision making procedure, and proper, compatible ones should be applied for electing projects on the basis of stated criteria.

\section{Methodology}

The study is conducted in Sadra Company, a ship manufacturing company, which performs largescale national projects and it is crucial for the company to achieve the highest possible quality. The related criteria were elicited from the related literature. Encountering countless and various criteria, ship manufacturing experts' consultancy was applied to discover the ship-industry-oriented criteria through fuzzy hypothesis test and questionnaires. In order to clarify the importance level of each of the criterion, paired comparison methods were applied by industry experts. Ultimately, their weights were elucidated by fuzzy network analysis. The study applied qualitative words and their associated fuzzy numbers. The values of parameters were transformed into triangular fuzzy numbers and they were used to calculate fuzzy values (Yager \& Filev, 1994) expressed in Table 1.

\section{Table 1}

Linguistic terms for the fuzzy rating (Srdjevic \& Medeiros, 2008)

\begin{tabular}{lcc}
\hline Linguistic definition & Priority of column to row & Priority of row to column \\
\hline Identical & $(1,1,1)$ & $(1,1,1)$ \\
Equal important to more importance & $(0.33 .0 .5,1)$ & $(1,2,3)$ \\
Rather more importance & $(0.2,0.33,1)$ & $(1,3,5)$ \\
Rather more importance to high importance & $(0.2,0.25,0.33)$ & $(3,4,5)$ \\
High importance & $(0.14,0.2,0.33)$ & $(3,5,7)$ \\
High importance to very high importance & $(0.14,0.17,0.2)$ & $(5,6,7)$ \\
Very high importance & $(0.11,0.14,0.2)$ & $(5,7,9)$ \\
Very high importance to thorough importance & $(0.11,0.13,0.14)$ & $(7,8,9)$ \\
Thorough importance & $(0.11,0.11,0.14)$ & $(7,9,9)$ \\
\hline
\end{tabular}

The decision matrix was composed and to gather the required information for proportional scores of each project, a special questionnaire was applied. The questionnaire indicated the score of each project in comparison to qualitative criteria. To prevent misunderstanding, complex and ambiguous phrase were either clarified or omitted. Appling the MADM approach, the projects were prioritized and their ultimate ranking was specified. In order to summarize the information related to statistical society, Table 2 illustrates the examinees classified on the basis of applied questionnaires.

\section{Table 2}

The examinees categorized according to applied questionnaires

\begin{tabular}{llll}
\hline Questionnaire title & Examinees & $\begin{array}{l}\text { Received } \\
\text { questionnaires }\end{array}$ & $\begin{array}{l}\text { Distributed } \\
\text { questionnaires }\end{array}$ \\
\hline $\begin{array}{l}\text { Selecting major prioritization criteria to } \\
\text { choose Six Sigma projects in Sadra Company }\end{array}$ & $\begin{array}{l}\text { Sadra company managers and } \\
\text { experts } \\
\text { university professors }\end{array}$ & 27 & 30 \\
\hline $\begin{array}{l}\text { Evaluating the relative importance of } \\
\text { influential criteria }\end{array}$ & $\begin{array}{l}\text { Sadra company managers and } \\
\text { experts }\end{array}$ & 6 & 8 \\
\hline $\begin{array}{l}\text { Indicating projects qualitative scores in } \\
\text { accordance with qualitative criteria }\end{array}$ & $\begin{array}{l}\text { Sadra company managers and } \\
\text { experts }\end{array}$ & 8 & 10 \\
\hline
\end{tabular}




\subsection{Selecting the major criteria in Six Sigma project selection}

Through profound digging of pertinent literature, the criteria were elicited. Those criteria, which were rather similar were screened and eliminated and finally, 15 criteria were chosen. In fuzzy assumption test, the hypothesis is not rejected or accepted completely, but the rate of its truth or falsity is declared. The hypothesis test is conceived on the basis of seven scales for each criterion. If the confirmation rate of hypothesis is called $\mathrm{H}_{1}, \ldots, \mathrm{H}_{6}, \mathrm{H}_{0}$, then some criteria are chosen as classification criteria $\left(\mathrm{M}_{1}+\mathrm{M}_{2}>2 / 3 \mathrm{M}_{0}\right)$. This amount is indicated in accordance with experts' idea.

Table 3

The final criteria to prioritize and select Six Sigma projects

\begin{tabular}{lllc}
\hline Column & Criteria & Code & Confirmation rate \\
\hline 1 & Project renting cost & $\mathrm{C}_{1}$ & 0.76 \\
2 & Project risk & $\mathrm{C}_{2}$ & 0.69 \\
3 & Project market share & $\mathrm{C}_{3}$ & 0.72 \\
4 & Project employees' competency & $\mathrm{C}_{4}$ & 0.74 \\
5 & Project process improvement & $\mathrm{C}_{5}$ & 0.72 \\
6 & Project managers' competency & $\mathrm{C}_{6}$ & 0.7 \\
7 & Project profitability & $\mathrm{C}_{7}$ & 0.7 \\
\hline
\end{tabular}

\subsection{Introducing Six Sigma projects}

Five projects were discussed for the companies which are itemized as follows,

$\mathrm{A}_{1}$ : Manufacturing process improvement

$\mathrm{A}_{2}$ : Management and administration process improvement

$\mathrm{A}_{3}$ : Inventory management and storage process improvement

$\mathrm{A}_{4}$ : Marketing process improvement

$\mathrm{A}_{5}$ : Product design and development process improvement

\subsection{Composing decision matrix}

After introducing the final criteria, decision matrix were composed. The amount; of qualitative criteria were clarified on the basis of professional.24 experts and university professors commend on each project performance for each criteria and then The linguistic variables were altered to fuzzy numbers. The specialists' ideas were averaged and the decision matrix was composed as illustrated in table5.

\section{Table 5}

Decision matrix each project score comparing to the final criteria

\begin{tabular}{|c|c|c|c|c|c|c|c|c|c|c|c|c|c|c|c|c|c|c|c|c|c|}
\hline \multirow{2}{*}{ Project } & \multicolumn{3}{|c|}{ C1 } & \multicolumn{3}{|c|}{ C2 } & \multicolumn{3}{|c|}{ C3 } & \multicolumn{3}{|c|}{$\mathrm{C} 4$} & \multicolumn{3}{|c|}{ C5 } & \multicolumn{3}{|c|}{$\begin{array}{l}\text { 66 } \\
\end{array}$} & \multicolumn{3}{|c|}{ C7 } \\
\hline & $\bar{L}$ & $\bar{M}$ & $\bar{U}$ & $\bar{L}$ & $\bar{M}$ & $\bar{U}$ & $\bar{L}$ & $\bar{M}$ & $\bar{U}$ & $\bar{L}$ & $\bar{M}$ & $\bar{U}$ & $\mathrm{~L}$ & $\bar{M}$ & $\bar{U}$ & $\bar{L}$ & $\bar{M}$ & $\bar{U}$ & $\bar{L}$ & $\bar{M}$ & $\bar{U}$ \\
\hline$\overline{\mathrm{A} 1}$ & 0.14 & 0.25 & 0.36 & 0.6 & 0.7 & 0.8 & 0.23 & 0.34 & 0.46 & 0.19 & 0.23 & 0.27 & 0.25 & 0.27 & 0.29 & 0.34 & 0.48 & 0.56 & 0.17 & 0.22 & 0.27 \\
\hline A2 & 0.46 & 0.67 & 0.78 & 0.47 & 0.68 & 0.79 & 0.31 & 0.33 & 0.35 & 0.12 & 0.17 & 0.22 & 0.2 & 0.25 & 0.3 & 0.11 & 0.19 & 0.27 & 0.2 & 0.21 & 0.22 \\
\hline A3 & 0.78 & 0.82 & 0.86 & 0.13 & 0.16 & 0.19 & 0.45 & 0.65 & 0.78 & 0.3 & 0.5 & 0.7 & 0.36 & 0.44 & 0.57 & 0.22 & 0.29 & 0.38 & 0.31 & 0.33 & 0.35 \\
\hline A4 & 0.15 & 0.32 & 0.49 & 0.11 & 0.21 & 0.35 & 0.16 & 0.26 & 0.36 & 0.11 & 0.14 & 0.17 & 0.22 & 0.33 & 0.44 & 0.56 & 0.64 & 0.76 & 0.12 & 0.15 & 0.23 \\
\hline A5 & 0.13 & 0.2 & 0.27 & 0.32 & 0.42 & 0.52 & 0.35 & 0.38 & 0.41 & 0.22 & 0.37 & 0.49 & 0.13 & 0.29 & 0.37 & 0.21 & 0.23 & 0.25 & 0.25 & 0.27 & 0.29 \\
\hline
\end{tabular}

M: medium limit, L: lower limit, U: upper limit

\subsection{Evaluating criteria weights}

In MCDM and multi attribute decision making (MADM) problems, awareness toward the relative significance of criteria or the aims is required. The total amount of them equals with the normalized unit and assesses the importance level of each criterion in comparison to the others. Fuzzy ANP is applied to evaluate the criteria weights. The idea based matrix introduced by Saaty and Takizawa (1986) was applied Instead of Saaty's super matrix. The uncertainty originated by examinee leads to 
appliance of fuzzy triangular numbers.to create compound matrix, geometric mean of specialists' ideas was used.

Table 6

Criteria weights trough Fuzzy ANP

\begin{tabular}{lll}
\hline Criteria & Normalized weights & Criteria weights \\
\hline Project renting cost & 0.1187 & 0.279899 \\
Project risk & 0.1561 & 0.367861 \\
Project market share & 0.1435 & 0.338298 \\
Project employees' competency & 0.1053 & 0.248287 \\
Project process improvement & 0.1500 & 0.353488 \\
Project managers' competency & 0.1557 & 0.366918 \\
Project profitability & 0.1708 & 0.40251 \\
\hline
\end{tabular}

As indicated in the table, the weights are close to each other, but the profitability criterion is slightly higher than the others are. Project risk is considered as the second important criterion. The mangers are eager to choose a project with the least risk but the highest possible profitability. The paired comparison questionnaire was applied to gather information. The incompatibility rate of the each of the matrix was calculated to assess the reliability. If the paired comparison matrix is reliable the fuzzy paired comparison would be comparison and vice versa (the concept is illustrated in Table 7).

\section{Table 7}

The incompatibility rate of paired comparison matrix

\begin{tabular}{ll}
\hline Paired comparison matrix related to the & Incompatibility rate \\
\hline Criteria not considering project cost & 0.024 \\
Criteria not considering project risk & 0.0056 \\
Criteria not considering project market share & 0.032 \\
Criteria not considering project employees' competency & 0.056 \\
Criteria not considering project process improvement & 0.0655 \\
Criteria not considering project managers' competency & 0.063 \\
Criteria not considering project employees' competency profitability & 0.022 \\
\hline Seven perspective & 0.021 \\
\hline
\end{tabular}

Since the consistency ratio for all components is less than 0.1 , the compatibility of the matrix is accepted.

\subsection{Project ranking on the basis of SAW technique}

According to Table 8, the third project is higher in grade compared with others, which means that inventory and storage process improvement could lead company to reach its objectives.

\section{Table 8}

Six Sigma Project prioritization applying SAW

\begin{tabular}{llll}
\hline Project & Grade & Certain weight & Fuzzy weight \\
\hline 1 & 4 & 1.166 & $(0.553,0.989,1.957)$ \\
2 & 5 & 0.854 & $(0.456,0.725,1.382)$ \\
3 & 1 & 1.648 & $(0.823,1.389,2.733)$ \\
4 & 2 & 1.357 & $(0.558,1.053,2.461)$ \\
5 & 3 & 1.243 & $(0.611,1.073,2.046)$ \\
\hline
\end{tabular}

\subsection{Project ranking on the basis of TOPSIS technique}

As illustrated in Table 9, the fourth project (marketing process improvement) attained the highest ranking, meaning that the company should concentrate on this project. In the second position product design and improvement process stands. 


\section{Table 9}

Six Sigma project weights and ranking through TOPSIS technique

\begin{tabular}{lcccc}
\hline Project & Grade & $c l_{i}$ & $d_{i}^{-}$ & $d_{i}^{+}$ \\
\hline 1 & 4 & 0.4882 & 4.4873 & 4.7043 \\
2 & 5 & 0.3876 & 3.3528 & 5.2980 \\
3 & 3 & 0.5912 & 5.4306 & 3.7553 \\
4 & 1 & 0.6451 & 5.5249 & 3.0397 \\
5 & 2 & 0.6032 & 5.2089 & 3.4272 \\
\hline
\end{tabular}

\subsection{Project ranking on the basis of VIKOR technique}

As expressed in Table 10, the fourth project poses a higher rank among the other projects. The company should concentrate on marking management process improvement, advertising and customer relationship management.

Table 10

Six Sigma project weights and ranking through VIKOR technique

\begin{tabular}{lccccccc}
\hline Project & Final ranking & Grade & Q & Grade & R & Grade & S \\
\hline 1 & 4 & 4 & 0.780 & 4 & 3.898 & 4 & 3.747 \\
2 & 5 & 5 & 0.999 & 5 & 4.273 & 5 & 4.273 \\
3 & 3 & 3 & 0.661 & 3 & 3.485 & 3 & 3.485 \\
4 & 1 & 1 & 0.000 & 1 & 2.366 & 1 & 2.366 \\
5 & 2 & 2 & 0.257 & 2 & 2.929 & 2 & 2.688 \\
\hline
\end{tabular}

\subsection{Project ranking on the basis of Borda technique}

Decision makers try to take advantage of various techniques to come to a better choice. Applying various techniques may lead to wide range of variety in results. To overcome this obstacle, some amalgamation techniques like Borda are introduced. Borda is based on the majority rule and conducted on the basis of paired comparison. Borda helps to compare the alternatives to each other. Table 11 expressed the results on the basis of majority rule in which $\mathrm{M}$ means a column is prior to a row and $\mathrm{X}$ means a row is prior to a column.

\section{Table 11}

The final prioritization of Six Sigma project applying Borda technique

\begin{tabular}{llllllll}
\hline Alternation & Project 1 & Project 2 & Project 3 & Project 4 & Project 5 & $\sum C$ & Final grade \\
\hline Project 1 & - & M & X & X & X & 1 & 4 \\
Project 2 & X & - & X & X & X & 0 & 5 \\
Project 3 & M & M & - & X & X & 2 & 3 \\
Project 4 & M & M & M & - & M & 4 & 1 \\
Project 5 & M & M & M & X & - & 3 & 2 \\
\hline
\end{tabular}

Borda suggests the final priority of projects and introduces the fourth project as the project with the highest priority. The company should focus on the marketing process, advertising and customer relationship improvement. Product design and development is the company second priority. The other projects are prioritized as follow: inventory management process improvement, manufacturing process improvement, administration process improvement.

\section{Results, discussions and conclusion}

As declared previously, the study has attempted to propose a method to prioritize and select Six Sigma projects in Sadra ship-manufacturing company. Encountering countless and various criteria, ship manufacturing experts' consultancy was applied to discover the ship-industry-oriented criteria through fuzzy hypothesis test and questionnaires. In order to clarify the importance level of each of the criterion, paired comparison methods were applied by industry experts. Ultimately, their weights 
of them were elucidated by fuzzy network analysis. The study applied qualitative words and their associated fuzzy numbers. The values of parameters were transformed into triangular fuzzy numbers and they were used to calculate fuzzy values. Seven criteria with confirmation rate (which is more than 0.67) were selected. Fuzzy ANP was applied and led to discuss profitability as the main criteria for project selection. Having calculated the weights pertinent to criteria through three methods (SAW, TOPSIS, and Fuzzy VIKTOR), Six Sigma projects were introduced and prioritized. Applying the three methods generated various results, which required the application of an amalgamation technique, entitled as Borda. Borda helped to clarify the final project rate. Borda has suggested the final priority of projects and introduced the fourth project as the project with the highest priority. The company should focus on the marketing process, advertising and customer relationship improvement. Product design and development was the company's second priority. The other projects were prioritized as inventory management process improvement, manufacturing process improvement, administration process improvement. The proposed approach can be regarded as a novel attempt in six sigma project selection which can be applied in various industries. More pertinent criteria for decision making can be discussed which lead to a better decision. Further researches may be conducted through various decision making techniques, apart from those applied in the present research. The logic laid underneath the present study may be checked to be applicable in different companies.

\section{References}

Adams, C. W., Gupta, P., \& Wilson, C. E. (2003). Six sigma deployment (Vol. 4). Routledge.

Azar, A., \& Fraji, H. (2008). Fuzzy Management Sciences, Tehran: Mehran Nashar Publication, [In Persian].

Coronado, R. B., \& Antony, J. (2002). Critical success factors for the successful implementation of six sigma projects in organisations. The TQM magazine, 14(2), 92-99.

Breyfogle III, F. W., Cupello, J. M., \& Meadows, B. (2000). Managing Six Sigma: a practical guide to understanding, assessing, and implementing the strategy that yields bottom-line success. John Wiley \& Sons. Cheng, J. L. (2008). Implementing Six Sigma via TQM improvement: an empirical study in Taiwan. The TQM Journal, 20(3), 182-195.

Büyüközkan, G., \& Öztürkcan, D. (2010). An integrated analytic approach for Six Sigma project selection. Expert Systems with Applications, 37(8), 5835-5847.

Brun, A. (2011). Critical success factors of Six Sigma implementations in Italian companies. International Journal of Production Economics, 131(1), 158-164.

Eckes, G. (2002). The Six Sigma revolution: How General Electric and others turned process into profits. John Wiley \& Sons.

Farsijani, H. (2010). World Class Manufacturing and Operations Techniques. Tehran: Samt Publication.

Han, C., \& Lee, Y. H. (2002). Intelligent integrated plant operation system for Six Sigma. Annual Reviews in Control, 26(1), 27-43.

Ingle, S., \& Roe, W. (2001). Six sigma black belt implementation. The TQM Magazine, 13(4), 273280.

Johnson, A., \& Swisher, B. (2003). How six sigma improves R\&D. Research Technology Management, 46(2), 12-15.

Köksalan, M. M., Wallenius, J., \& Zionts, S. (2011). Multiple criteria decision making: from early history to the 21st century. World Scientific.

Linderman, K., Schroeder, R. G., Zaheer, S., \& Choo, A. S. (2003). Six Sigma: a goal-theoretic perspective. Journal of Operations management, 21(2), 193-203.

Montgomery, D. C. (2001). Introduction to Statistical Quality Control, $4^{\text {th }}$ Edition. John Wiley, NY.

Nonthaleerak, P., \& Hendry, L. (2008). Exploring the Six Sigma phenomenon using multiple case study evidence. International Journal of Operations \& Production Management, 28(3), 279-303. 
Neuman, R. P., \& Cavanagh, R. (2000). The six sigma way: How GE, Motorola, and other top companies are honing their performance. McGraw Hill Professional.

Pyzdek, T. (2003). The six sigma project planner. A Step by Step Guide to Leading a Six Sigma Project Through DMAIC.

Ruffa, S. A. (2008). Going lean: How the best companies apply lean manufacturing principles to shatter uncertainty, drive innovation, and maximize profits. AMACOM Div American Mgmt Assn.

Saaty, T. L., \& Takizawa, M. (1986). Dependence and independence: From linear hierarchies to nonlinear networks. European Journal of Operational Research, 26(2), 229-237.

Snee, R. D. (2004). Six-Sigma: the evolution of 100 years of business improvement methodology. International Journal of Six Sigma and Competitive Advantage, 1(1), 4-20.

Srdjevic, B., \& Medeiros, Y. D. P. (2008). Fuzzy AHP assessment of water management plans. Water Resources Management, 22(7), 877-894.

Szeto, A. Y., \& Tsang, A. H. (2005). Antecedents to successful implementation of Six Sigma. International Journal of Six Sigma and Competitive Advantage,1(3), 307-322.

Tadikamalla, P. (1994). The confusion over six sigma. Quality Progress, 27(1183), 83-85.

Van Pelt, M. (2008). Fuzzy Logic Applied to Daily Life. Seattle, WA: ISBN 0-252-16341-9.

Wessel, G. (2003). A Comparison of Traditional TQM Methodologies with the Six Sigma Approach for Quality Management. Six-Sigma-Quality. de, Hamburg, available at: www. wesselgo. de/sixsigma/reference/SSQ2_Differ ence_TQM_SixSigma. pdf (accessed 15 April 2008).

Yager, R. R., \& Filev, D. P. (1994). Essentials of fuzzy modeling and control. New York.

Zadeh, L. A. (1968). Fuzzy algorithms. Information and control, 12(2), 94-102. 